\title{
Research Trajectory in Digital Health - A Retrospective Study on a Masters Programme in Biomedical Informatics in Sri Lanka.
}

Pandula Anilpriya Siribaddana a ()

\begin{abstract}
Introduction: In most Low- and Middle-Income Countries, research output related to digital health is not adequate. In some instances, the output from the established research programmes may not match the needs. In Sri Lanka, a masters degree programme in Biomedical Informatics ("masters") aimed at medical doctors from the state health sector is a key contributor to the research output in digital health. The programme which is conducted by the Post Graduate Institute of Medicine has trained nearly 180 medical doctors. This study intends to understand the evolving research output of the above programme and the causalities for the evolution from 2011 to 2020.
\end{abstract}

Method: The study gathered publicly available data pertaining to theses submitted by graduates of the masters from the library of the Postgraduate Institute of Medicine. It also gathered historical data through published records and from authors own recollections about the evolution of the programme until 2020 from its inception. An interpretivist approach was used in analysing the data and deriving the conclusions.

Results and Analysis: The study identified 166 research titles published as dissertations by the graduates of the programme from 2011 to 2020 . These research titles belong to six key areas in digital health; public health informatics, clinical informatics, policy and governance, education informatics, bioinformatics, and pharmacy informatics. Yearly research output varied depending on the number of students in the batch and due to other factors including available opportunities, changing programme priorities, funding opportunities, trainer capacity and evolving digital health landscape of the country. While the research output was dominated by 'policy and governance' and 'bioinformatics' related research at the beginning, the output is currently dominated by 'public health informatics' and 'clinical informatics' related research.

Conclusion: The research output from the programme indicates a strong focus on public health and clinical informatics related research. Evolving health information systems may have contributed to the growing interest as it creates opportunities for further research.

Keywords: health informatics, biomedical informatics, education, training, digital health

\section{INTRODUCTION}

Digital health has become a buzz word in many forums especially after the adoption of the WHO digital Health Strategy in 2017. It encompasses but not limited to well-known and sometimes overlapping areas of study such as e-health, m-health, telehealth, telemedicine, health information systems, health informatics and related areas such as digital health governance and policy. With a growing emphasis on digital health ecosystems and digital health leadership, the importance of research around digital health hardly needs to be mentioned.

However, low and middle-income countries (LMICs) have been grappling with the issue of context-specific research studies particularly in a field such as digital health ${ }^{(1)}$. Even when a Postgraduate Institute of Medicine, University of Colombo, Sri Lanka

Correspondence to: Dr Pandula Anilpriya Siribaddana,

Postgraduate Institute of Medicine, University of Colombo, Sri Lanka

pasiribaddana@yahoo.com

ORCID ID:

https://orcid.org/00000002-9131-3971

\section{Article history:}

Received 13 November 2020 Revised 27 December 2020 Accepted 28 December 2020 Published 30 December 2020

DOI:

http://doi.org/10.4038/sljb mi.v11i2.8101 (c) This is an open access article licensed under a Creative Commons Attribution-Share Alike 4.0 International License (CC BYSA 4.0), which permits unrestricted use, distribution and reproduction in any medium, provided the original author and source are attributed and materials are shared under the same license.

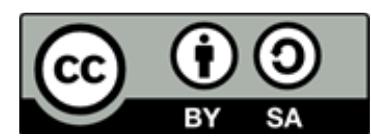


research programmes are implemented in these settings, it is unclear as to how and to what extent such programmes contribute toward understanding the interplay between technology and context(2). This would mean that practitioners and researchers alike in LMICs would still have to depend on research evidence emerging from other contexts, which may not truly represent the socio-cultural, socio-political and technological landscape of a particular context.

The Masters programme in Biomedical Informatics was established in 2008 at the Postgraduate Institute of Medicine (PGIM) of the University of Colombo. One of its aims was to strengthen the research capacity in digital health in the country. The programme has so far produced around 180 graduates up to 2020 and a similar number of research projects ${ }^{(3)}$. However, there has not been a review of the research emerging from the programme and therefore this study aimed to evaluate the research output from the programme to identify areas of contribution, the changing trajectory and the factors that may have contributed to the said trajectory in Sri Lanka.

\section{METHOD}

The study was retrospective in nature as it looked into the research output generated from the master's programme over the last 10 years (2011 to 2020). The titles of the theses published by the graduates of the master's programme were obtained from the archives of the PGIM library. The gathered titles were then qualitatively analysed in order to classify the research done into key areas as recognised by the American Medical Informatics Association (AMIA) ${ }^{(4)}$ ].

Following identifying the key areas in biomedical informatics to which the graduate researchers have contributed, the author explored possible explanations to the changing research trajectory observed at different points in time. Given that the author of the study has been involved in the master's programme since its inception, decisions that led to the changing trajectory of research output were identified through recalling historical accounts and reviewing secondary literature. However, the author was sensitive to the potential bias that may arise in recalling historical accounts and thereby sought clarification from two members of the Speciality Board in Biomedical Informatics who have also been part of the programme since its inception. The secondary literature referred included conference proceedings and booklets published by the health informatics society of Sri Lanka (HISSL) ${ }^{(5)}$, which explain the changing digital health landscape in the country. The documented history of the programme in secondary literature also allowed the author to verify historical accounts - further alleviating the potential for bias.

Based on the identified research output, the changing trajectory over time and the historical accounts on key decisions made on the course of the last 10 years, the study derived its conclusions in an interpretive manner.

\section{RESULTS AND ANALYSIS}

The study identified 166 theses published between 2011 and 2020 by the graduates of the master's programme. The number of publications differed from year to year as the intake to the master's also changed. Figure 1 shows the number of research work completed and submitted in the form of a thesis by the graduates of the masters.



Figure 1: Thesis completed by graduates of the master's from 2010 to 2020

As illustrated in Figure 1, the number of theses completed fell to a low of 6 in 2016 before it increased to a maximum of 28 in 2019.

Research titles extracted were classified into key areas in health informatics. As illustrated in Table 1, these areas included; public health informatics, clinical informatics, bioinformatics, policy and governance, education informatics and pharmacy informatics.

As illustrated in Table 1, the largest proportion of contribution to the research output was from clinical informatics $(n=56,33.7 \%)$ and public health informatics $(n=51,30.7 \%)$. Contribution to areas of bioinformatics, education informatics and policy and governance were $12.7 \% \quad(n=21), \quad 10.8 \% \quad(n=18)$ and $10.8 \% \quad(n=18)$ respectively. The least contribution among the categories 
identified was for the pharmacy informatics, which was only $1.2 \%(\mathrm{n}=2)$.

When looking into the contribution to each recognised category over time, a changing trajectory was noted. Figure 2 illustrates the yearly contribution in the form of theses for each of the areas in biomedical informatics recognised earlier.

Table 1: Cumulative research output from 2011 to 2020 from the master's programme

\begin{tabular}{|lrc|}
\hline \multicolumn{1}{|c}{ Area of Focus } & $\begin{array}{r}\text { Number } \\
\text { of theses }\end{array}$ & $\begin{array}{c}\text { Proportion } \\
(\mathbf{\%})\end{array}$ \\
\hline clinical Informatics & 56 & 33.7 \\
\hline public Health Informatics & 51 & 30.7 \\
\hline pharmacy Informatics & 2 & 1.2 \\
\hline education Informatics & 18 & 10.8 \\
\hline bioinformatics & 21 & 12.7 \\
\hline policy and Governance & 18 & 10.8 \\
\hline Total Research Output & $\mathbf{1 6 6}$ & $\mathbf{1 0 0 . 0}$ \\
\hline
\end{tabular}

As illustrated in Figure 2, most of the graduates from the first batch have embarked on research work around policy and governance $(n=10,38.5 \%)$ and bioinformatics $(n=9$, $34.6 \%)$. With time, it was observed that the focus on public health informatics and clinical informatics were increasing. The cumulative contribution from these two research areas remained over $75 \%$ from the total research output although the two informatics areas alternated each year as the more dominant field of study. The output concerning policy and governance and bioinformatics declined following its dominance in 2011 and remained low throughout the years.

The study also recognised several key events that took place since the inception of the master's programme. These are listed in Table 2.

While many decisions were made by the Speciality Board that may have impacted the research output, Table 2 depicts some of the key events that took place between 2008 and 2020, which were documented in the related literature.

\section{DISCUSSION}

It was noted that each year, the programme maintained an intake of maximum 30, which explains the reason for the number of submissions not exceeding 30 at any point. It was also recognised through historical accounts that until 2015 , there wasn't a clear career pathway for the doctors who complete the masters. In 2016, a new MD programme in Health Informatics was implemented by the PGIM. It allowed graduates of the masters to obtain specialist qualifications through board certification. One may
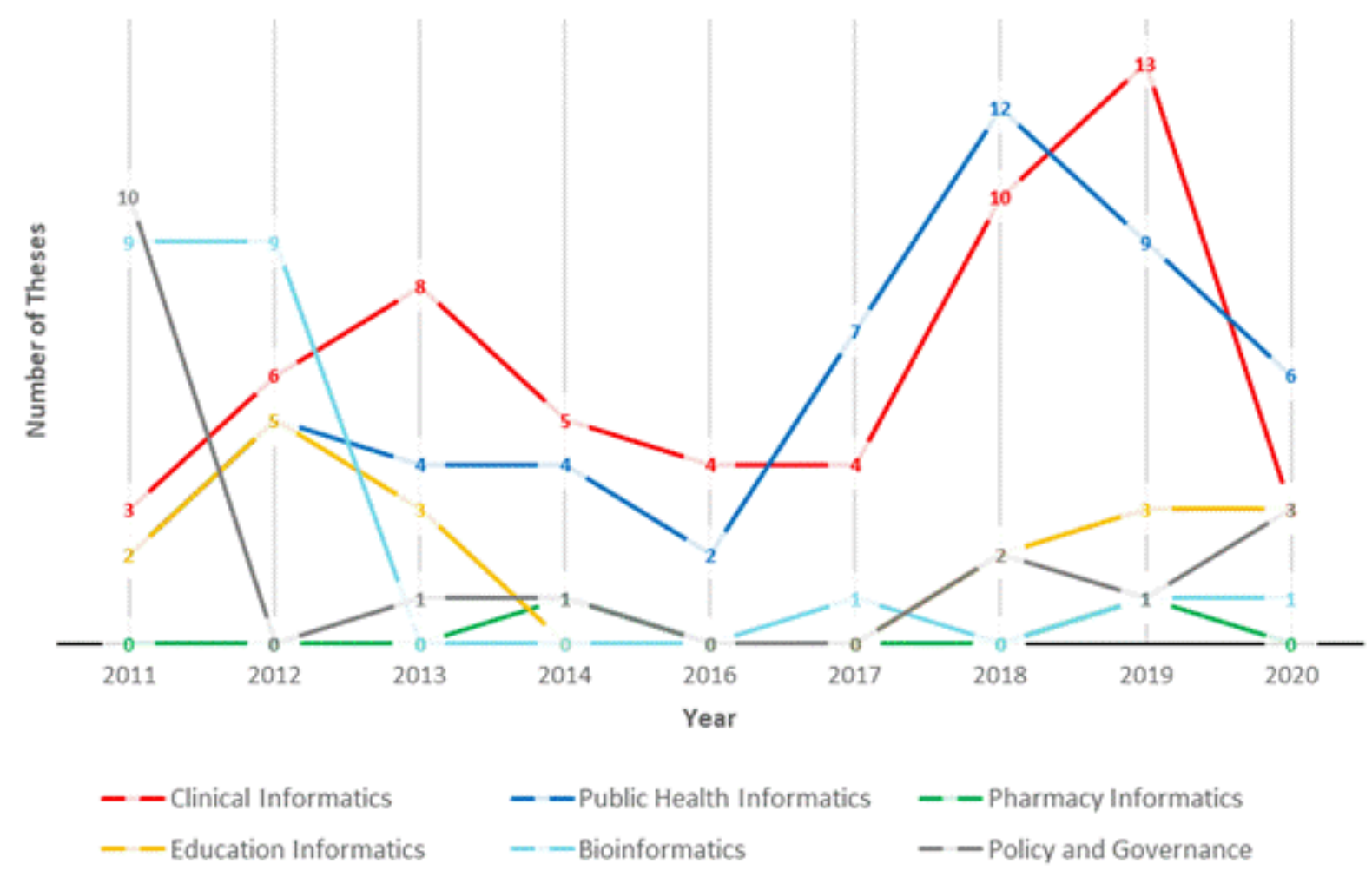

Figure 2: Areas of Study Among MSc BMI Graduates from 2011 to 2020 
Table 2: Historical events relevant to the changing research trajectory of the master's programme

\begin{tabular}{ll}
\hline \multicolumn{1}{|c|}{ Year } & \multicolumn{1}{c}{ Event } \\
\hline 2008 & Funding availability through an international grant \\
\hline $2009 / 2010$ & Launch of the master's programme \\
\hline $2009 / 2010$ & Implementation of the e-IMMR system \\
\hline 2010 & Setting up of the National e-health steering committee \\
\hline 2010 & Launch of the Sri Lanka Journal of Biomedical Informatics \\
\hline 2010 & Inaugural e-health Sri Lanka conference \\
\hline 2012 & Conclusion of the international grant \\
\hline 2013 & Revision of the master's curriculum \\
\hline 2013 & Creation of the National e-health base documents \\
\hline 2013 & Implementation of the HIMS \\
\hline 2013 & Commissioning of DHIS2 based health information system for the National Programme for \\
\hline 2016 & Tuberculosis Control and Chest Diseases (NPTCCD) \\
\hline 2016 & Return of resource persons with doctoral qualifications in health informatics \\
\hline 2016 & Launch of the MD programme \\
\hline
\end{tabular}

2016/ 2017 Implementation of electronic reproductive health information management system (e-RHIMS)

2018/2019 First batch of senior registrars starting foreign training as Commonwealth Digital Health Fellows at the University of Southampton, UK.

attribute the renewed interest in the master's programme from 2017 onwards to the opening of the career pathway although the drop in 2020 cannot be explained as yet.

The research output from the master's programme may be indicative of the digital health research carried out with a focus to align with digital health needs of the state health sector in Sri Lanka. The reason for this assumption is that the said master's being the only programme to offer research-based degrees to health staff of the Ministry of Health in biomedical informatics - doctors. In addition, the programme was influenced by the Scandinavian action research approach(6) as the University of Oslo played a major role in providing domain expertise for setting up the programme. This intends that from the very beginning, trainees were expected to engage in practice-oriented research that would focus on resolving health information gaps residual within the healthcare setting.

At the beginning of the programme, there was a significant emphasis on assessing and finding measures to overcome the challenges within the healthcare system as against developing and implementing health information systems. As a result, many of the early research studies contributed to the 'policy and governance' category in health informatics. This may partly be due to the lack of operational health information systems within the state health sector and less mature ground support to implement digital systems. However, the absence of health information systems also created opportunities for the trainees to engage in action research, where research outcomes were aimed at fulfilling the needs within the state health sector. For example, the eIMMR was developed initially as a student project and was later adopted by the Ministry of Health as the main method of reporting indoor morbidity and mortality data to the centre(5). The tradition was maintained throughout as trainees engaged in research that was driven by the digital health needs within the health sector resulting in both new solutions as well as extensions of existing solutions (e.g., extension of the e-RHIMS) ${ }^{(5-7)}$. 
The shape of the research output was also contributed to by the multidisciplinary nature of the Speciality Board in Biomedical Informatics, which supervised the programme. It was also augmented by setting up of an e-health steering committee by the ministry, which was represented by some members of the Speciality Board. This meant that digital health needs within the ministry were effectively communicated to the Board and the Board was able to identify learning opportunities in the form of research and development and potential training sites - for targeted investment ${ }^{(7)}$. The Norad's Programme for Master Studies (NOMA) fund, which was available at the beginning of the programme enabled the board to support research initiatives in such a way that the sites in which such research was carried out could also be developed to accommodate future training needs. The decision to fund research studies and establish the basic infrastructure (e.g., internet connectivity and computers) may have laid the foundation to promote further research and facilitated new training units to emerge.

While not all research projects undertaken by the trainees gave rise to publications, many did make use of the opportunities created by the e-health conferences and the Sri Lanka Journal of Biomedical Informatics (SLJBMI), as these became the key means of disseminating research work ${ }^{(7)}$. These avenues may have also generated opportunities for the trainees to take their research to the world, use it as a means of networking and generate collaborations that would pave the way towards further research ${ }^{(8)}$.

As the programme matured, the focus on public health informatics and clinical informatics increased. Changing priorities within the programme also meant that the focus on policy and governance aspect of health informatics remained low. With the introduction of the MD programme, the research component of the master's programme was looked at as an opportunity for the trainees to engage in the actual development and implementation of health information systems rather than a theoretical exercise. Such engagement could contribute to developing the competencies necessary by a digital health practitioner cum leader ${ }^{(9)}$ - a key outcome expected through the programme. When the capacity among the trainers was enhanced with the return of resource persons with doctoral qualifications, the capacity to support trainees who undertake research in public health and clinical informatics was also enhanced. This emphasises the importance of capacity development in research among staff members and digital health practitioners who can facilitate the research and practice linking their own contexts $^{(10)}$

In the middle years, it was noted that the research output decreased proportionately to the lowering intake. Historical accounts suggest that this was partly due to the non-existence of a career path for the master's graduates, which was later rectified by the launch of the MD programme. With increasing intake, the disparity in the research output towards different fields of study became more apparent. This was evidenced by more than $75 \%$ contribution towards public health and clinical informatics as against other fields of study. The greater contribution to public health and clinical informatics may be largely attributed to the changing needs within the state health sector and the more organised ground support to develop and implement problem specific health information systems as student projects. However, the evolution of the health information systems such as the HIMS and the eRHIMS within the state health sector may also be attributed to the dominant focus on public health and clinical informatics(3-5). These systems not only created learning opportunities but also enabled branching research that contributes to further expansion of the said systems. Nevertheless, this study was not intended to identify the personal preferences among the researchers, which may have also influenced the research undertaking.

\section{CONCLUSION}

The masters programme in biomedical informatics at the PGIM is one of the main contributors to the digital health research in Sri Lanka. Over the last decade, it has generated more than 166 research-based dissertations out of which many have been published in peer-reviewed journals and conference proceedings. The research focus has been changing from 2011 with the initial focus being on policy and governance related research. However, at present, public health informatics and clinical informatics related research dominate the landscape. The study recognised that evolving nature of health information systems within the state health sector, more established ehealth policies, capacity among trainers and the linking between research with emerging and ongoing digital health needs in the healthcare system have contributed to the changing trajectory of research focus.

With the growing attention on telemedicine platforms and $\mathrm{m}$-health around the world and in Sri Lanka, it is expected that the focus would continue to change in the future, with a heavy emphasis on clinical informatics. A more detailed 
evaluation is proposed in order to identify the impact of the research on the digital health landscape in Sri Lanka. Such an evaluation will help plan how the research focus shall change in future, further enhancing the contribution of the programme to fulfil the national digital health needs.

\section{ACKNOWLEDGEMENT:}

The author would like to acknowledge the contribution made by the Speciality Board in Biomedical Informatics of the Postgraduate Institute of Medicine, University of Colombo in managing the Master of Science in Biomedical Informatics programme and for its support for this study. The support extended by the Library of the PGIM and the master's graduates who provided details pertaining to their research are also acknowledged.

\section{REFERENCES}

1. English M, Irimu G, Agweyu A, Gathara D, Oliwa J, Ayieko $\mathrm{P}$, et al. Building Learning Health Systems to Accelerate Research and Improve Outcomes of Clinical Care in Low- and Middle-Income Countries. PLOS Medicine. 2016 Apr 12;13(4):e1001991.

2. Byrne E, Donaldson L, Manda-Taylor L, Brugha R, Matthews A, MacDonald S, et al. The use of technology enhanced learning in health research capacity development: lessons from a cross country research partnership. Globalization and health. 2016;12(1):114.

3. Siribaddana P, Hewapathirana R, Jayatilleke AU, Sahay S, Dissanayake VH. Strengthening health systems through informatics capacity development among doctors in low-resource contexts: the Sri Lankan experience. WHO South-East Asia journal of public health. 2019;8(2):87-94.

4. Kulikowski CA, Shortliffe EH, Currie LM, Elkin PL, Hunter LE, Johnson TR, et al. AMIA Board white paper: definition of biomedical informatics and specification of core competencies for graduate education in the discipline. Journal of the American Medical Informatics Association. 2012;19(6):931-938.

5. Digital Health in Sri Lanka 'Sustainable Implementation of Digital Health Solutions through Local Capacity Building' [Internet]. Health Informatics Society of Sri Lanka (HISSL); 2017. Available from: http://www.hissl.lk/Digital_Health_SL_19982017.pdf

6. Rasmussen LB. Action research-Scandinavian experiences. AI \& Soc. 2004 Jan 1;18(1):21-43.

7. Hewapathirana R, Sahay S, Jayatilleke AU, Dissanayake VH, Siribaddana P. 'Hybrid Doctors' Can Fast Track the Evolution of a Sustainable e-Health Ecosystem in Low Resource Contexts: The Sri Lankan Experience. Studies in health technology and informatics. 2019;264:1356-1360.
8. Chapman E, Haby MM, Toma TS, de Bortoli MC, Illanes E, Oliveros MJ, et al. Knowledge translation strategies for dissemination with a focus on healthcare recipients: an overview of systematic reviews. Implementation Science. 2020;15(1):1-14.

9. Parkin P. Managing change in healthcare: Using action research. Sage; 2009.

10. Sahay S, Sundararaman T, Braa J. Public health informatics: designing for change-a developing country perspective. Oxford University Press; 2017. 